\title{
TRANSVERSALIDADE E ESQUIZOANÁLISE
}

TRANSVERSALITY AND SCHIZOANALYSIS

TRANSVERSALIDAD Y ESQUIZOANÁLISIS

\author{
Eduardo Simonini* \\ Roberta Carvalho Romagnoli*
}

\begin{abstract}
RESUMO
Neste trabalho, procuramos discutir o conceito de transversalidade na obra de Félix Guattari (e seus desdobramentos na esquizoanálise) e a apropriação deste conceito feita pelo sociólogo René Lourau (e seus desdobramentos na análise institucional ou socioanálise). Dessa maneira, primeiramente, apresentamos a transversalidade como Guattari a compreendeu em suas teorizações iniciais sobre grupos, para, depois, estendermos as discussões a 1) como esse conceito se associa à esquizoanálise, quando da valorização das tramas que promovem a invenção de inéditas estéticas existenciais; e 2) como a transversalidade se associa à análise institucional ou socioanálise, quando do desvelamento do inconsciente institucional. Concluímos que, apesar dos usos diferentes que os referidos autores realizam da concepção de transversalidade, ambos sustentam que tal conceito comunga com a perspectiva de se pensar a realidade como produção política, múltipla e plural, abrindo sujeitos e grupos a novos tipos de crises, críticas e possibilidades.
\end{abstract}

Palavras-chave: Transversalidade. Esquizoanálise. Análise institucional.

\begin{abstract}
In this essay we discuss the concept of transversality in Félix Guattari's works (and their developments in the schizoanalysis) and the appropriation of this concept by the sociologist René Lourau (and its development in the institutional analysis or socioanalysis). In this way, we first present the transversality as Guattari understood it in his initial theories about groups, and then we extend the discussions to 1) how this concept is associated with the schizoanalysis, when valuing the plots that promote the invention of unprecedented existential aesthetics; and 2) how the transversality is associated with the institutional analysis or the socioanalysis, when unveiling the institutional unconscious. We finally conclude that, despite the different uses that the mentioned authors carry out on the concept of transversality,

\footnotetext{
Texto recebido em 20 de março de 2015 e aprovado para publicação em 13 de fevereiro de 2016.

Doutor em Educação e mestre em Psicologia Social pela UERJ, professor no Departamento de Educação e no Programa de Pós-Graduação em Educação da Universidade Federal de Viçosa/MG, psicólogo. E-mail: simonini198@gmail.com.

** Pós-doutora em Análise Institucional pela Universidade Cergy-Pontoise (França), doutora em Psicologia Clínica pela PUC SP, mestra em Psicologia Social pela UFMG, professora no programa de Pós-Graduação em Psicologia da PUC Minas, pesquisadora do CNPq e da Fapemig, psicóloga. E-mail: robertaroma1@gmail.com.
} 
both maintain that this concept communes with the perspective of thinking reality as a political production, multiple and plural, opening subjects and groups to new types of crisis, criticisms and possibilities.

Keywords: Transversality. Schizoanalysis. Institutional analysis.

\section{RESUMEN}

En este trabajo buscamos discutir el concepto de transversalidad en la obra de Félix Guattari (y sus desdoblamientos en el esquizoanálisis) y la apropiación de este concepto hecha por el sociólogo René Lourau (y sus desdoblamientos en el análisis institucional o socioanálisis). De esta manera, primero presentamos la transversalidad tal como Guattari la comprendió en sus teorizaciones iniciales sobre grupos, para luego extender las discusiones a 1) cómo este concepto se asocia al esquizoanálisis, en relación con la valorización de las tramas que promueven la invención de inéditas estéticas existenciales; y 2) cómo la transversalidad se asocia al análisis institucional o socioanálisis, en relación con el desvelamiento del inconsciente institucional. Concluimos que, a pesar de los usos diferentes que los referidos autores realizan del concepto de transversalidad, ambos sostienen que tal concepto concuerda con la perspectiva de pensar la realidad como producción política, múltiple y plural, abriendo sujetos y grupos a nuevos tipos de crisis, críticas y posibilidades.

Palabras clave: Transversalidad. Esquizoanálisis. Análisis institucional.

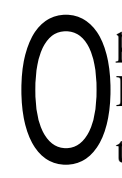

psicanalista francês Pierre-Félix Guattari apresentou, no I Congresso Internacional de Psicodrama, realizado em 1964, na cidade de Paris, um texto intitulado "A transversalidade" (Guattari, 2004). Até então mais conhecido por suas ações de militância política, por suas discussões no campo da análise institucional ${ }^{1}$ e ainda por suas iniciativas em uma clínica psiquiátrica chamada La Borde, Guattari sustentou, na apresentação do referido trabalho, que o conceito de transferência e sua associação com o complexo de Édipo eram insuficientes para se lidar com a clínica institucional.

Em um aspecto mais geral, a transferência é compreendida como sendo o movimento de transladar algo de um lugar para outro, sendo que, no campo de trabalho da psicanálise, por transferência se entende o processo de revivência, na cena analítica, de um afeto (geralmente inconsciente) que é deslocado de seu ponto de origem no passado para, muitas vezes, ser encarnado na figura do analista. Essa transferência, e a consequente interpretação desta, configurase como o motor do processo de análise psicanalítica. Nesse sentido, Sigmund Freud assume que:

\footnotetext{
1 De acordo com Lourau (2004a, p. 49), "O sentido estrito do conceito de instituição é posto em questão, pois já recobre inúmeros níveis de realidade. Em particular: a) instâncias individuais ou coletivas com organização diferenciada; b) códigos escritos ou não escritos, mais ou menos acompanhado de um aparelho jurídico ou organizacional”.
} 
A transferência surge espontaneamente em todas as relações humanas e de igual modo nas que o doente entretém com o médico; é ela, em geral, o verdadeiro veículo da ação terapêutica, agindo tanto mais fortemente quanto menos se pensa em sua existência. A Psicanálise, portanto, não a cria; apenas a desvenda à consciência e dela se apossa a fim de encaminhá-la ao termo desejado (Freud, 1910/1996, p. 62)2 .

$\mathrm{O}$ processo psicanalítico envolve, entre outros aspectos, a interpretação e a reconstrução no presente da repetição transferencial, favorecendo com que o que antes era vivido de maneira inconsciente seja conscientemente percebido e ressignificado. Para Freud, a dinâmica dessa repetição sustenta a sintomatologia neurótica e "é tarefa do analista tirar constantemente o paciente da ilusão que o ameaça e mostrar-lhe sempre que o que ele toma por uma vida nova e real é um reflexo do passado" (Freud, 1938/1996, p. 191). Portanto, pelo caráter repetitivo da dinâmica transferencial, as circunstâncias em torno do complexo de Édipo tendem a ser constantemente reatualizadas na transferência, já que, muitas vezes, o analista é colocado pelo paciente no lugar de um dos pais. E, para Freud,

Se o paciente coloca o analista no lugar do pai (ou mãe), está também lhe concedendo o poder que o superego exerce sobre o ego, visto que os pais foram, como sabemos, a origem de seu superego. $\mathrm{O}$ novo superego dispõe agora de uma oportunidade para uma espécie de pós-educação do neurótico; ele pode corrigir erros pelos quais os pais foram responsáveis ao educá-lo (Freud, 1938, p. 190).

Quando Freud se refere ao fato de os pais serem os principais responsáveis pela construção do superego dos filhos, ele alude à dimensão na qual a resolução do complexo de Édipo está intrinsecamente relacionada a como o indivíduo viverá a experiência da frustração de perder (ou não) sua onipotência no seio da família. Isso porque, numa resolução "sadia" do Édipo, o indivíduo tem frustrada a fantasia de possuir só para si um de seus pais, e essa frustração advém do receio de ser punido em tal desejo; punição esta que se refere a ser submetido, de acordo com a psicanálise freudiana, à castração de seu órgão sexual (complexo de castração). Esse medo à castração funda o núcleo do superego, o qual é formado pelo primeiro grande "não" social a que uma criança é submetida: a proibição do incesto. Dessa maneira, o complexo de castração, ao fundar o núcleo do superego, igualmente funda as condiçóes psíquicas para uma vida em sociedade, uma vez que, para se viver em comunidade, é necessário o reconhecimento da existência de limites; o reconhecimento de que não se pode tudo e que existe um outro, uma alteridade, um "não eu" diante do qual há a necessidade de negociação de espaços e ações.

Contudo, para Guattari (2004), o movimento de interpretação que o psicanalista faz dessa repetição transferencial muitas vezes surge esvaziado de componentes

2 A primeira data indica o ano de publicação original da obra, e a segunda, a edição consultada pelo autor e só será pontuada na primeira citação da obra no texto. Nas seguintes, será registrada apenas a data de publicação original. 
políticos e sociais, apresentando-se apenas como uma reatualização imaginária de uma circunstância passada: geralmente uma cena familiar de fundamentação edípica. Para além da redução das dinâmicas transferenciais ao teatro familiar, Guattari (2004) insistirá que há impasses sociais e políticos que se fazem singulares no presente (não seguindo o roteiro de uma repetição ritual do passado) e que, no transversalizar um indivíduo, muitas vezes não têm condições de serem resolvidos no consultório de um psicanalista; onde geralmente se pratica a redução da subjetividade ao psiquismo. O psicanalista, se muito centrado em uma mitologia edípica, tende a ignorar e, ou, desconsiderar questôes outras que tomam forma em circunstâncias completamente exteriores à cena analítica. Para Guattari (2004):

As dimensões mais graves das neuroses que os psicanalistas pretendem atingir são, pelo contrário, evitadas por eles, pela boa razão de que eles não se veem diante delas no consultório. Há elementos interpretativos a ser apreendidos nos elos cambiantes da sociedade. [...] É ainda importante não perder de vista, por exemplo, que uma imensa Spaltung (cisão) se instaurou recentemente no mundo comunista, o que complicou todas as nossas estruturas de referência: há a paranoia dos chineses, a parafrenia dos albaneses, a perversão dos revisionistas, etc. Para não poucas pessoas na sociedade, isso conta! Se for cego para todas as coisas dessa ordem e pretender que não fazem parte do campo de análise, é impossível o psicanalista ter acesso a certos problemas, não só certos problemas políticos, mas também à axiomática inconsciente que é comum a pessoas que vivem na sociedade real (p. 72).

É ilustrativo desse contexto o exemplo que Deleuze, seu parceiro em outras obras, ${ }^{3}$ traz, inspirado nas considerações de Guattari, quando apresenta:

Eis um caso. Uma mulher chega para uma consulta. Ela explica que toma tranquilizantes. Pede um copo com água. Depois fala: "Compreende, tenho uma certa cultura, estudei, gosto muito de ler, e no entanto: neste momento passo meu tempo a chorar. Já não posso suportar o metrô [...] E choro, mal leio qualquer coisa [...] Vejo a televisão, vejo as imagens do Vietnã: já não posso suportar [...]" O médico não responde grande coisa. A mulher prossegue: "Fiz a Resistência ${ }^{4}[. .$.$] um pouco: fui caixa para as cartas".$ O médico pede uma explicação. "Sim, não compreende, doutor? Chegava a um café e perguntava, por exemplo: há qualquer coisa para René? Davam-me uma carta para transmitir [...]" O médico ouve "René", desperta: "Por que é que disse René?" É a primeira vez que se interessa por uma questão. Até aqui ela tinha fala de metrô, de Hiroshima, do Vietnã, do efeito que tudo isso lhe provocava no seu corpo, o seu desejo de chorar. Mas o médico pergunta apenas: "Olha, olha, René [...] o que é que René evoca?” René, alguém que renasceu? o renascimento? A Resistência nada significa para o médico, mas o renascimento entra no esquema universal, o arquétipo: "Você quer renascer”. O médico encontra-se aí: finalmente, o seu circuito. E força-a a falar de seu pai e de sua mãe (Deleuze, 2006, p. 342).

\footnotetext{
3 Gilles Deleuze e Félix Guattari escreveram juntos "O anti-Édipo", "Kafka: por uma literatura menor", "Mil platôs" e "O que é a Filosofia”.

4 Resistência francesa.
} 
Toda uma análise da dimensão complexa do social, do político, do econômico e do poder surge fragilizada quando se insiste em priorizar apenas a repetição transferencial do complexo de Édipo no intuito de explicar a organização do psiquismo e da vida em sociedade. Por sua vez, contra a hegemonia desse modelo edípico (com sua produção de culpa e moralidades como dinâmicas fundantes do social), Guattari (2004) insistirá na frágil compatibilidade contemporânea entre a função paterna (elemento fundamental no processo de castração no Édipo) e as exigências da sociedade capitalista. Em Guattari, o modelo edípico do pairei-deus tendeu a perder sua efetiva função paterna na atualidade, ${ }^{5}$ uma vez que, segundo ele, as questôes da analítica do poder passam a serem desencarnadas de entidades jurídicas específicas (como o Estado, a Igreja e a Família), da mesma forma que a problemática de um indivíduo em particular não pode ser reduzida a um psiquismo individualizado e deslocado da trama social na qual ele se insere.

No pensar de Guattari, os tempos atuais trazem dinamismos em que o poder se apresenta como uma experiência difusa, rizomática, dispersa em fatores diversos, dependentes de arranjos plurais e tantas vezes transnacionais. Assim, "É preciso distinguir cuidadosamente o poder real do poder manifesto. O problema da relação de forças reais requer análise: todos sabem que o Estado não faz a lei em seus ministérios" (Guattari, 2004, p. 112). Da mesma maneira, um indivíduo não se faz apenas em sua biologia, em sua fisiologia, em suas redes neuronais, em sua relação familiar pequeno-burguesa ou nas especificidades de uma luta de classes, mas no transversalizar de diferentes dimensões de subjetivação.

Mesmo, pois, considerando a noção de transferência institucional - na qual tantas vezes se (re)vive a repetição edípica da totêmica figura de autoridade de um pai castrador para dentro das dinâmicas dos grupos de trabalho (sejam em suas dimensões profissionais ou terapêuticas) - Guattari (2004) propôs a transversalidade como uma ferramenta conceitual no processo de seguir outras tramas que vitalizam grupos. Transversalidade esta que, por sua vez, se oporia tanto à verticalidade grupal (com suas estratificações piramidais e hierárquicas) quanto às dinâmicas horizontalizadas, em que um setor tende a se organizar nas contingências de seu campo situado, no cultivo, por exemplo, de uma "coesão grupal" a propor uma política identitária.

Para além da verticalidade hierarquizante e da horizontalidade niveladora de perspectivas, a transversalidade já remeteria a uma dimensão mais conectiva, colocando em análise estratos diversos e descontínuos a atravessar um determinado sujeito ou grupo. Diante disso, Guattari, em suas primeiras aproximaçóes do tema, considera que a transversalidade tem a ver com o

\footnotetext{
5 A não ser quando reaparece nas regressões mistificadoras presentes na idealização imaginária da figura do "pai-salvador" nos regimes fascistas, ditatoriais, de representação pessoal, dentre outros que enaltecem a figura identitária de um líder como encarnação do poder fálico.
} 
quanto um grupo consegue "observar" seu funcionamento como mais complexo do que mera submissão a uma hierárquica autoridade ou limitado a arranjos horizontalizados de uma estabilidade identitária. Nesse contexto, uma psicanálise política tenderia a aumentar o coeficiente de transversalidade, ou seja, promover uma maior fluidez institucional, uma vez que atenta ao trabalho inconsciente que se opera em diferentes dimensões de uma dada situação analítica. Esse inconsciente, porém, liberta-se do Édipo familiar e se lança na trama das instituições, do social, das diversas estéticas de vida, das políticas que fomentam intervenções mundiais. Nesse sentido, Fourquet (2007) enfatiza que o conceito de transversalidade igualmente se articula com a crença de Guattari na existência de uma subjetividade social mundial detentora de vida e de desejo, e que opera transversalmente aos grandes conjuntos institucionais hierarquizados que pretendem governar o mundo. Segundo François Fourquet (2007), o conceito de transversalidade trouxe a novidade de associar os problemas psiquiátricos aos problemas sociais, políticos, planetários..., uma vez que o poder asilar de um hospital poderia ser assumido como um decalque do próprio modelo hierárquico piramidal da sociedade capitalista moderna.

Dessa maneira, na ampliação de uma dimensão transversal, a analítica de um grupo se mostra mais conectada a elementos complexos, históricos, sociais, político-econômicos, estéticos..., favorecendo com que esse mesmo grupo tome posse, de uma forma cada vez mais consistente, de sua própria voz. A esse grupo cuja transversalidade se apresentava ampliada, Guattari (1987) definiu como sendo "grupo sujeito", em contraposição ao "grupo sujeitado" ou "grupo objeto", cujas leis de funcionamento lhe vinham de instâncias exteriores. Apostando na dimensão autoprodutora da vida, esse autor insiste no deslocamento do grupo para produzir novas realidades, quando este se torna grupo sujeito, sustentado por movimentos em transversalidade que se caracterizam numa comunicação máxima a se efetuar entre os diferentes níveis e, sobretudo, em diferentes sentidos (Guattari, 1987).

O grau de transversalidade de um grupo se refere, portanto, ao "grau de cegueira" de seus membros; sendo que por este termo podemos entender a capacidade e, ou, limitação que um grupo possui de compor relações para além dos fatos e significados empiricamente estabelecidos nele e para ele. Isso porque "enquanto se mantêm imobilizadas em si mesmas, as pessoas só podem ver a si mesmas" (Guattari, 2004, p. 111), tornando-se, portanto, "cegas" a outros arranjos de sentido que podem vir a ganhar consistência quando da problematização (tantas vezes tensa e caótica, e angustiante) das referências então estabelecidas. O que faz com que, em uma análise institucional, o aumento do coeficiente de 
transversalidade se refira igualmente à ampliação dos agenciamentos desejantes, ${ }^{6}$ podendo esse processo evoluir para uma desorganização e, ou, para a construção de novos universos de referência.

Portanto, enquanto o conceito de transferência conversa com a neurose em seu aspecto de repetição, o conceito de transversalidade conversa com a psicose em seu aspecto de multiplicação. Se a transferência conduz ao campo de ação da psicanálise, a transversalidade conduz a um outro campo de problematização, ao da esquizoanálise. Em uma definição sempre provisória, Guattari propôs a esquizoanálise não como uma disciplina fechada em si mesma, mas como "A análise da incidência de disposiçōes de enunciação sobre as produçôes semióticas e subjetivas em um contexto problemático dado" (Guattari, 2000, p. 32, tradução nossa). Por disposições de enunciação, o autor considerou os agenciamentos capazes de forjar novas coordenadas no fazer existir de representaçõos e, ou, proposições inéditas. Os conceitos de "disposição de subjetivação" ou "disposição de enunciação" surgem em Guattari como substitutos ao conceito de "inconsciente", por este estar tantas vezes atrelado à perspectiva de um sujeito individuado. Assim Guattari procura extrapolar o problema dessa individualização do psiquismo ao compreender os sujeitos e grupos como emergentes em disposições de subjetivação/enunciação que se tramam no interagir de domínios muitas vezes radicalmente heterogêneos. Dessa maneira, "O enfoque esquizoanalítico nunca se limitará a uma interpretação dos "dados"; interessar-se-á, de maneira muito mais fundamental, [...] pelas disposições que promovem a concatenação dos afetos de sentido e dos afetos pragmáticos" (Guattari, 2000, p. 33, tradução nossa)

Melhor explicando, na esquizoanálise:

Trata-se de explorar e de retomar produtivas zonas de semiotização que não somente têm a tarefa de se articularem umas com as outras, de pôr em correspondência plurívocas coleçõos: 1) de figuras de expressão, 2) de entidades mentais, 3) de objetos referidos (reais ou virtuais), mas também, como suplemento a essas funçôes clássicas de representação e denotação, enganchar uma função de existencialização, característica das pragmáticas ontológicas e que consiste em desdobrar e em concatenar intensamente qualidades existenciais específicas. Basta-me, nessa etapa, assinalar que os índices intensivos, os operadores diagramáticos implicados por essa função existencial, não têm nenhum caráter de universalidade. [...] São mais cristais de singularização, pontos de bifurcação fora das coordenadas dominantes, a partir das quais podem surgir universos de referência mutantes (Guattari, 2000, p. 52, tradução nossa).

6 Com base nas consideraçôes de Deleuze e Guattari, Fuganti (1991, p. 56) apresenta que "O desejo é o próprio agenciamento ou relação. É por isso que você pode afirmar que ao desejo nada falta, seus objetos não são fantasmas e nem tampouco ele os produz. [. . .] [O desejo] é pleno em si mesmo, pois não existe previamente ao seu objeto, mas nasce simultaneamente com seu duplo objeto. O desejo emerge no meio, é um elemento relacional, uma liga de fluxos. Se ele tem objeto, este é o próprio fluxo. O desejo não se aloja na 'substância' de nenhum dos termos ligados por ele”. 
A análise da transversalidade, em Guattari, constitui-se, portanto, na própria dimensão esquizoanalítica, uma vez que se compromete no seguir as coordenadas de subjetivação e de singularização que transversalizam e ultrapassam um indivíduo ou grupo, na composição de sentido-ações a oportunizar outras trajetórias de realidade potencialmente inéditas. Dessa forma, se, em suas primeiras teorizações, Guattari (2004) sustentava que a transversalidade é o instrumento de ação de um grupo sujeito, no decorrer de sua obra e no movimento de compor a transversalidade com a esquizoanálise, Guattari abandonou o conceito de "grupo sujeito", indicando mais a necessidade de se priorizar, no processo de análiseintervenção, as disposições de subjetivação/enunciação emergentes, uma vez que um grupo é apenas um meio em que tais disposições circulam. Segundo ele:

Certa vez, eu vim com a ideia de "grupo sujeito" na tentativa de definir modos de intervenção os quais descrevi como micropolíticos. Eu mudei de ideia: não há grupos sujeitos, mas agenciamentos de enunciação, de subjetivação, agenciamentos pragmáticos que não coincidem com grupos circunscritos. Esses agenciamentos podem envolver indivíduos, mas também formas de ver o mundo, sistemas emocionais, máquinas conceituais [...], elementos de todos os tipos (Guattari, 1996, pp. 227-228, tradução nossa).

Se a análise da transversalidade pode também levar em consideração as repetiçôes transferenciais a se fazerem ressoar em diferentes níveis de um processo de produção individual e, ou, coletiva, em meio a essas mesmas repetições também avançam composições de subjetivação que singularizam ritmos, movimentos e práticas, enunciando agenciamentos a estranhar constâncias já estereotipadas em seu repetido decalque.

Dessa maneira, pensar no movimento da transversalidade na prática esquizoanalítica é considerar que um sujeito (ou grupo) só se compõe no urdir de disposições de subjetivação que ativam enunciaçõos que são efeitos de agenciamentos sempre coletivos. Foi diante de tal orientação de pensamento que, em 1991, quando visitava o Chile, Félix Guattari estabeleceu um diálogo com o poeta Juan Luís Martínez. Este último, durante o conversar, questionou Guattari sobre o uso que este fez do conceito de "eu" em seus trabalhos, ao que ele respondeu, rompendo com qualquer aporte às lógicas individualizantes, que:

Não falo de "eu", mas de territórios existenciais que integram o eu, o corpo, o espaço transicional, o espaço ambiental, a etnia, os ancestrais; há uma aglomeração não discursiva que faz com que alguém se integre à existência mediante todo tipo de dimensões, de intensidades [...] (Guattari, 1998, p. 149, tradução nossa).

Há, assim, em Felix Guattari, uma divergência com o postulado moderno da experiência do "eu": interiorizado, intimidade encarnada e tantas vezes 
reduzida a uma peculiaridade biológico-hormonal-cerebral. Para ele, o império do eu-indivíduo-interiorizado nos afasta da concepção política e transversal da existência, uma vez que o eu interiorizado (entidade serializada, registrada, modelada) não é sinônimo de subjetividade (dimensão em multiplicidade e agenciamentos). $\mathrm{O}$ eu proposto por Guattari (e aqui podemos incluir também "o grupo", "a sociedade”, "a cultura”, "a estética”, "a sexualidade”, "a empresa”, "a escola", "a linguagem" [...]) emerge como efeito das composições transversais de heterogêneas disposições de subjetivação.

Diferente, portanto, de uma filiação com Descartes, que centralizava a experiência do "eu" no ato de pensar, a perspectiva esquizoanalítica de Guattari nos parece mais aliada a consideraçôes que acompanham lógicas de transversalidade como as que emergem na literatura de Hermann Hesse, quando este anuncia que "Na realidade, não há nenhum eu, nem mesmo no mais simples não há uma unidade, mas um mundo plural, um pequeno firmamento, um caos de formas, de matizes, de situações, de heranças e possibilidades" (Hesse, 1993, p. 64).

Quando, pois, passamos a acompanhar usos no Brasil do conceito de transversalidade, temos que este começou a ser utilizado a partir da influência daqueles que, envolvidos com movimentos institucionalistas (sobretudo no campo da saúde coletiva e da saúde mental), embasaram suas produçôes nos trabalhos esquizoanalíticos de Félix Guattari, mas também na "análise institucional" ou "socioanálise" de René Lourau.

Ao realizar uma análise genealógica do movimento institucionalista no Brasil, Rodrigues (1999) situa sua implantação nos últimos anos da década de 1970, especialmente no eixo Rio de Janeiro-São Paulo, tendo uma maior atenção ao campo da saúde mental. Era essa área marcada por uma crescente defesa de práticas grupalistas com articulação interdisciplinar e associadas a setores populares. Igualmente L'Abbate, Mourão e Pezzato (2013) destacam a forte influência sobretudo da "análise institucional" de René Lourau nas ações de pesquisa e intervenção no campo da saúde coletiva também na década de 1970. Essa influência se deu no contexto do movimento da reforma sanitária, objetivando construir novas formas de articulação entre os diferentes campos de atenção à saúde.

Contudo as concepções institucionalistas não ficaram restritas à saúde mental ou à saúde coletiva, mas se espalharam no campo da educação, da assistência social, do trabalho, entre outras áreas. Nesse contexto, observamos usos distintos do conceito de transversalidade. Por um lado, temos que ele foi utilizado como o fez Guattari (1987), quando insistiu que a ampliação do coeficiente de transversalidade caracterizava a ação do grupo sujeito: sujeito de sua própria 
gestão. Nesse sentido, apostar na transversalidade era resistir à reprodução cronificada de hierarquizações ou à sua naturalização. $\mathrm{O}$ que fazia com que a análise da transversalidade se comprometesse com o tecer questionamentos, em diferentes níveis de enunciação, às relações de poder hegemonizadas, a fim de se conseguir chegar a um ponto de tensão analítica em que um grupo problematizasse suas próprias referências, interferências, fantasias, motivações e impotências, tornando-se sujeito de sua trajetória.

Essa leitura da transversalidade é usada como recurso epistemológico para se pensar a complexidade da vida, das tramas sociais e de seus consequentes desdobramentos quando do delinear de ferramentas de intervençãoexperimentação nos campos da promoção de saúde, da autonomia dos usuários, da desinstitucionalização da loucura, do enfretamento das vulnerabilidades, da violência escolar, entre outros. Assim, na prática intersetorial em um hospital, a transversalidade se ampliaria, por exemplo, quando médicos, enfermeiros, nutricionistas, técnicos, fisioterapeutas, administradores, psicólogos, funcionários, pacientes... se atrevessem ao desafio de questionar seus locais de naturalizada identidade. Passariam, então, além de problematizar os ritmos normalizadores que os construíram institucionalmente em papéis delimitados (doente-criança; médico-Deus-pai; corpo-objeto; enfermeiro-polícia, entre outros), a se experienciarem provocados a criar-experimentar dispositivos de ação que promovessem outras disposições de subjetivação favorecedoras do partejar de novos regimes relacionais.

Por sua vez, a transversalidade também foi utilizada a partir das apropriações que o sociólogo René Lourau fez do referido conceito. Segundo este:

Oriundo das pesquisas psicoterápicas e psicanalíticas de Guattari, este conceito [a transversalidade] foi ampliado por nossa tendência. Designa o que aparece parcialmente na pré-intervenção ou pré-enquête que antecede a intervenção e, sobretudo, no próprio decurso da intervenção, a saber: o entrecruzamento de pertencimentos e referências (sociais, econômicas, ideológicas, políticas) do coletivo constituído pelo grupocliente e pelo(s) socioanalista(s). [...] A descoberta da transversalidade é descoberta de conflitos, de lutas sociais: ela própria é uma fonte de conflitos, porque lugar das resistências do não dito (Lourau, 2004b, pp. 132-133).

Lourau igualmente entende que a transversalidade diz respeito ao desmonte de hierarquias instituídas em um grupo, uma vez que se estabelece no intercruzamento dos pertencimentos e na ampliação das zonas de conflito. Esse uso prevê ainda que a transversalidade potencializa o processo grupal e permite deslocamentos nas intervenções institucionais, sobretudo porque associa, em um mesmo nível, elementos heterogêneos que podem vir a desnudar o inconsciente institucional, 
chamado por ele de "não dito". Este "não dito" que a análise da transversalidade auxilia a desvendar é, para Lourau, produto de uma repressão social a produzir um inconsciente social. Aquilo que se censura é a palavra social e a vontade de mudança, o que faz com que a socioanálise tenha como referência os trabalhos de denúncia do "não dito" tanto em Karl Marx quanto em Sigmund Freud: o primeiro denuncia a instituição da mais-valia capitalista, que fica encoberta pela alienação do trabalhador; e o segundo denuncia as racionalizações que ocultam as forças "silenciosas" do inconsciente (Lourau, 2004c). Dessa maneira, Lourau (1995, p. 270) considera que "a transversalidade reside no saber e no não saber do agrupamento a respeito de sua polissegmentaridade. É a condição indispensável para passar do grupo-objeto ao grupo-sujeito".

Essa abordagem da transversalidade como instrumento de desvendamento do "não dito" institucional favoreceu, por exemplo, com que Baremblitt (1992) oferecesse uma positividade ao conceito de transversalidade, opondo-o a seu negativo: o conceito de atravessamento. Por atravessamento ele considerará a interpenetração dos elementos a serviço do instituído, da resistência, da reprodução, enquanto, por sua vez, considerará a transversalidade como sendo a interpenetração entre as diferentes forças comprometidas com a novidade, com a inovação e com as rupturas das lógicas estabelecidas; forças estas qualificadas como instituintes.

Nesse contexto, tanto Baremblitt (1992) quanto Guillier (2003) consideram que a transversalidade emerge na socioanálise de Lourau como um dos principais princípios metodológicos de sua intervenção em organizações. A elucidação dessa transversalidade em uma análise institucional diz respeito ao exame das afiliações dos participantes da intervenção em referência aos muitos grupos, categorias, ideologias e outras peculiaridades de pertencimento que percorrem tanto analistas quanto a organização analisada, e se ligam ao sistema social mais amplo. E como a instituição reproduz as relações sociais dominantes dentro de uma coletividade particular, a análise da transversalidade encontra tanto processos de resistência quanto também vetores de subjetivação que podem apontar para o novo.

Porém, mesmo Lourau assumindo a análise da transversalidade como sendo uma etapa numa metodologia de intervenção institucional, ${ }^{7}$ a transversalidade foi um conceito pouco teorizado pelo sociólogo, uma vez que substituído pelo de "implicação". Esta absorve a noção de transversalidade quando coloca em análise as disposições de subjetivação do grupo interventor em ação num contexto específico, revelando o que a instituição deflagra naqueles que nela intervêm, que, por sua vez, são também "eus" plurais, pois efeitos de uma

\footnotetext{
7 Intervenção esta que, além da fase da "elucidação da transversalidade", traz consigo outros tópicos como a "análise da oferta", "análise da demanda", a "autogestão da intervenção", a "regra de tudo dizer e da livre expressão", a "análise das implicações do pesquisador-profissional”, a "construção e elucidação dos analisadores".
} 
produção sempre coletiva de valores, interesses, expectativas, desejos e crenças. Para Lourau (2004b, p. 133), a "implicação":

Requer a análise do saber conscientemente dissimulado e do não saber inconsciente próprio de nossas relações com a instituiçãa. [...] Em seguida, a implicação veio a designar também todas as determinaçôes transversais ao estabelecimento onde tem lugar a análise institucional.

Se por um lado, contudo, René Lourau se apropria do conceito de transversalidade (e de seu desdobramento na "implicação") para utilizá-lo como método de sua análise-intervenção institucional, a transversalidade não se compõe necessariamente como uma ferramenta de definida metodologia no trabalho esquizoanalítico de Guattari. Este evita criar roteiros específicos na delimitação de um "objeto", uma vez que:

Nossa preocupação principal consiste em desenvolver um marco conceitual que previna a esquizoanálise contra qualquer tentação de se abandonar ao ideal de cientificidade que prevalece ordinariamente nos domínios "psi” à maneira de um Superego coletivo. [...] Disso emerge a necessidade de construir inteiramente dispositivos de enunciação analíticos - que não deixam de ter relação com os da criação artística - para voltar a encontrar a eficácia (Guattari, 2000, pp. 48, 52-53, tradução nossa).

Assim, em Guattari, a transversalidade que se trama à esquizoanálise comunga mais com as dimensões estéticas da criação-experimentação artística do que com os enquadres de um método ansioso por trazer às luzes da razão uma verdade ocultada (um "não dito" sufocado) em um inconsciente individual ou institucional. $\mathrm{O}$ ativar da transversalidade, em Guattari, não se constitui em um método de pesquisa, mas em uma abertura à experimentação desejante, a qual não é assumida como "algo" a ser acossada por uma ação interpretativa, mas como intensidade a ser seguida em arranjos potencialmente singulares. A esquizoanálise se assume na transversalidade (nessas composiçōes agenciadas em heterogênese) não para denunciar dimensões inconscientes não ditas, mas para fazer passar uma multiplicidade a abrir caminhos para futuros a serem inventados. O que nos recorda um diálogo estabelecido entre Umberto Eco e Jean-Claude Carrière, em que estes consideram que:

Não há nada como o maluco para produzir interpretação. Ou a interpretação para produzir o maluco. Esta é a contribuição dos surrealistas, que trabalhavam para aproximar palavras sem nenhum parentesco, ou relação, para fazer irromper um sentido oculto (Eco \& Carrière, 2010, p. 149).

$\mathrm{Na}$ análise institucional de Lourau, a transversalidade vem a ser esse elemento a colocar na vizinhança pluralidades a fim de oportunizar vazão a esse "sentido oculto" a que se referem Eco e Carrière (2010), e que René Lourau (2004c) 
chamou de "não dito" institucional. Já na esquizoanálise de Guattari, se a transversalidade coloca em proximidade zonas dissonantes em sentido e ausentes de qualquer semiótica anastomose, o ponto-chave não é mais fazer emergir sentidos oculto-reprimidos, mas produzir novos sentidos, inéditas cognições, o que tende a gerar estranhamentos e a aproximar, como já argumentado, a intervenção esquizoanalítica da criação artística.

Entretanto, nos diferentes usos que fizeram, os trabalhos de Guattari e Lourau nos conduzem à perspectiva de que as dimensões em transversalidade jogam inexoravelmente com multiplicidades, pluralidades e com o entendimento de que nenhum "objeto" ou sujeito é expressão neutra, "pura”, não miscigenada. Tudo é trama na transversalização de linhas em diversidade que podem tanto estabilizar identidades provisórias quanto se acelerarem na "caotificação" das referências e trajetórias. O compromisso que se faz é com o seguir, inventar e compor arranjos produtores de realidades que enunciam modos diversos, inéditos e incertos de agir-pensar a potencializar outras maneiras de existir. Estas não têm um roteiro definido e, nutridas em lógicas desejantes a articularem transversalmente heterogeneidades, podem tanto estabilizar inéditas trajetórias de subjetivação quanto também fomentar acelerações e, ou, paralisias abortivas de horizontes. 


\section{REFERÊNCIAS}

Baremblitt, G. F. (1992). Compêndio de análise institucional e outras correntes: teoria e prática. Rio de janeiro: Rosa dos Tempos.

Deleuze, G. (2006). A ilha deserta e outros textos. São Paulo: Iluminuras.

Eco, U. \& Carrière, J-C. (2010). Não contem com o fim do livro. Rio de Janeiro: Record.

Fourquet, F. (2007). Une intuition de Félix Guattari. Revue du Mauss, 29(1), 555-568.

Freud, S. (1910). Cinco lições de Psicanálise. In J. Salomão (Trad.), Edição standard das obras psicológicas completas de Sigmund Freud (Vol. 11, pp. 25-65). Rio de Janeiro: Imago, 1996. (Publicado originalmente em 1910).

Freud, S. (1938). Esboço de Psicanálise. In J. Salomão (Trad.), Edição standard das obras psicológicas completas de Sigmund Freud (vol. 23, pp. 151-229). Rio de Janeiro: Imago, 1996. (Publicado originalmente em 1938).

Fuganti, L. A. (1991). Saúde, desejo e pensamento. In A. Lancetti (Org.), Saúde loucura 2. (pp. 19-82). São Paulo: Hucitec.

Guattari, F. (1987). Revolução molecular: pulsaçôes politicas do desejo. São Paulo: Brasiliense.

Guattari, F. (1996). Soft subvertions. New York: Semiotext(e).

Guattari, F. (1998). El devenir de la subjetividad. Santiago de Chile: Dolmen.

Guattari, F. (2000). Cartografías esquizoanaliticas. Buenos Aires: Manantial.

Guattari, F. (2004). Psicanálise e transversalidade: ensaios de análise institucional. Aparecida: Ideias e Letras.

Guillier, D. (2003). L'analyse des implications dans les pratiques socianalytiques : celles de l'analyste ou/et celles de son client ?. L'Homme et la société, 147(1), $35-53$.

Hesse, H. (1993). O lobo da estepe. Rio de Janeiro: Record.

L'Abbate, S., Mourão, L. C. \& Pezzato, L. M. (2013). A análise institucional e a saúde coletiva no Brasil. São Paulo: Hucitec. 
Lourau, R. (1995). A análise institucional. Petrópolis: Vozes.

Lourau, R. (2004a). O instituído contra o instituinte. In S. Altoé (Org.), René Lourau: analista institucional em tempo integral. (pp. 47-65) São Paulo: Hucitec.

Lourau, R. (2004b). Uma apresentação da análise institucional. In S. Altoé (Org.), René Lourau: analista institucional em tempo integral. (pp. 128-139). São Paulo: Hucitec.

Lourau, R. (2004c). Objeto e método da análise institucional. In S. Altoé (Org.), René Lourau: analista institucional em tempo integral. (pp. 66-86). São Paulo: Hucitec.

Rodrigues, H. B. C. (1999). Notas sobre o paradigma institucionalista: preâmbulo político-conceitual às aventuras históricas de "sócios" e "esquizos" no Rio de Janeiro. Transversóes, 1(1), 169-199. 